Presidential Address *

\title{
Expanding medical education for better child care
}

\author{
Chandra Abeysekera ${ }^{1}$ \\ Sri Lanka Journal of Child Health, 2007; 36: 127-9
}

(Key words: expanding education, child care)

Expanding medical education for better child care is the mission that I am planning to accomplish during my term in office and I hope to focus on this topic in my presidential address as well.

Education is the platform on which knowledge, attitude and skills are acquired and is not a venture that ends with receiving a degree. Proper education should be an exciting, continuous and lifelong pursuit. In the 1970's, John Holt, an educationist, in his thought provoking book titled 'What do I do Monday' makes the following comments about the process of learning ${ }^{1}$.

"Learning is reaching out into the world around us. We can only grow from where we are. If we don't know where we are, we can hardly move at all with any sense of direction or purpose". This statement illustrates the importance of first knowing where we are before we proceed to higher levels ${ }^{1}$.

The society in general and the medical profession in particular demand that professionals in whom they have invested continue to learn and contribute towards continued professional development. On this basis continued education appears to be an essential tool for professionals to have a positive impact on the health of individuals and populations.

On July 4 1900, Sir William Osler, a Canadian physician, and one of the greatest icons of modern medicine, in a major address in London, said "More clearly than any other, the physician should illustrate the truth of Plato's saying, that education is a lifelong process." The message is that what is learned in medical school is inadequate and would only provide the graduate with an incomplete knowledge for professional development ${ }^{1}$.

Osler clearly perceived that professionals need "refreshment, renovation and constant upgrading of knowledge, attitude and skills as an antidote against premature senility and redundancy. Daily contact with the bright young minds of our associates and good rapport with medical societies are important.

\footnotetext{
${ }^{1}$ Senior Lecturer, Head Department of Paediatrics, University of Peradeniya.

*Address given on induction as President SLCP, July 2007.
}

There are no limits and barriers to learning. One can learn from one's superiors, from peers and subordinates ${ }^{1}$.

History of the world wars is an example of the opportunities that were available to those who were willing to learn.

An explosion of research relating directly to medicine began in this era. In the early decades of the twentieth century it became apparent that there existed a wide gap between the good medical care provided by knowledgeable physicians and the routine practices of those whose learning ended with the attainment of a medical degree.

Now let me take you on a voyage of discovery in the management of urinary tract infections (UTIs), a topic which is of special interest to me, to view the developments from the ancient methods to current management strategies. I hope to highlight the importance of knowing the latest developments in the practice of medicine to provide better care for patients.

One of the oldest written medical records is from ancient Egypt, the Ebers papyrus. It describes more than 900 diseases and contains recommendations for treatment, including several herbs for urine retention and excessive urination. However, the coverage of urological disorders in ancient Egyptian medical literature is limited ${ }^{2}$.

In ancient Greece patients were treated by the gods in the temples. With time these temples developed into the medical schools of Cnidos. A book attributed to the Cnidian school of medicine, describes 4 renal diseases of which one was most likely to be an acute renal infection ${ }^{2}$.

Hipppocrates, the father of clinical medicine, combined the knowledge of the Cnidian school of medicine with his own and created the foundation for scientifically sound, evidence based medicine. The Hippocratic collection too has descriptions of renal diseases that appeared to be UTIs.

With the death of Hippocrates the Greek physicians migrated to Rome where they replaced the ancient Roman system of magic based medicine. An ancient Roman medical book describes the treatment for 
kidney diseases that included warm hip baths, purgatives, dietary modification and herbal remedies.

According to the Susruta Samhita, written in the 6th century in India, treatment for an illness resembling UTI consisted of herbs and other remedies like goat and even human urine ${ }^{2}$.

Although microbial aetiology of infectious diseases was finally discovered in the $19^{\text {th }}$ century physicians did not recognise the role of bacterial organisms in aetiology of UTI for many years. The breakthrough occurred during the $20^{\text {th }}$ century, the discovery of antibiotics was the single most important advance that made a difference to the patient ${ }^{3}$.

The era of modern, evidence based urology began in the $20^{\text {th }}$ century with the first trials of chemotherapeutic agents. Other strategies such as bacteriophages, vaccines and antitoxins have also been explored ${ }^{3}$.

In 1931, Robert Hutchison, in his book titled 'Lectures on Diseases of Children', defines UTI in childhood as an infection by the Bacillus coli. As the bowel is the primary source of infection one mode of treatment was to disinfect it. If inflamed, the appendix was removed. Bladder washout was performed in cystitis. Urine was alkalinised using citrate of potash. If this treatment was ineffective a vaccine, prepared from the urine of the patient was tried. In resistant cases the child's nutritional status was improved to allow time for healing ${ }^{4}$.

Even during the 1930's fatalities following UTI have even been reported in premier children hospitals in the world like Great Ormond Street Children's Hospital, London.

Rapid advances made during the next ten years in the diagnosis, imaging techniques, surgical procedures and microbial therapy have dramatically changed the approach to management from essentially palliative care to evidence based strategies.

Guidelines for management of UTI were developed through personal experience of expert clinicians and scientific hypothesis. With the new knowledge gathered from published randomised controlled studies the guidelines were subjected to frequent change.

UTI is a common problem in children and is considered a serious disease resulting in the scarring of kidneys leading to chronic renal failure. Since 1991 I have been involved in the management of children with UTI and have witnessed the changing scenario of the management guidelines 5 .

We followed the guidelines of the working group of the research unit, Royal College of Physicians, the nephrology paediatric group of the Indian Academy of
Paediatrics $^{6}$ and the American Academy of Paediatrics $^{7}$.

My initial experience in 1991 was that it was necessary to extensively investigate children with UTI to detect those with underlying VUR which predisposes them to renal scarring. Prophylactic antibiotics were prescribed until the age of 5-7 years and regular 3 monthly urine cultures were performed even if they were asymptomatic ${ }^{8}$.

But subsequent clinical studies unravelled a genetic link in the pathogenesis of VUR, renal dysplasia and reflux nephropathy and the scars that were initially thought to result from UTI were of congenital origin ${ }^{9}$.

A systematic review of randomised controlled trials of interventions for children with VUR questions the long term benefits of such interventions.

A large multicentre randomised controlled trial in the United Kingdom to compare medical versus surgical treatment of UTI has not demonstrated any difference in outcome ${ }^{10}$

In the same vein, early treatment of asymptomatic bacteriuria has not shown any benefit. In fact it could be even harmful due to the risk of developing resistant organisms.

With the introduction of the paediatric renal transplantation programme in the Teaching Hospital, Peradeniya in 2004, I had the opportunity of studying children with chronic kidney disease. It was brought to light that the aetiology of the disease in a majority of the transplanted children was due to congenital abnormalities ${ }^{11}$.

In the light of new knowledge concerning the aetiology of renal scars and the controversies on the effect of interventions for VUR, children with UTI are subjected to minimal invasive investigations at present. Micturating cystourethrogram (MCUG), an invasive procedure, is reserved for special circumstances. Routine urine cultures in asymptomatic children are not indicated as they do not require therapy. Controversies exist on the beneficial effects of the use of prophylactic antibiotic therapy.

The latest article published in the Journal of the American Medical Association in July 2007 indicates that antimicrobial prophylaxis was associated not with decreased risk of recurrent UTI, but with increased risk of resistant infections.

Ladies and gentleman,

I have shown you the developments that occurred over the centuries in the management of UTI. The world is changing everyday with new developments in every sphere of medicine and this is just one example. Although it's hard to keep pace with the current developments in the world, to make a strong impact 
on the care provided to our patients we need to upgrade knowledge.

In this rapidly developing world, where access to the internet is freely available, patients are able to obtain information about their diseases. Thus, the clinician must be one step ahead and must know the latest developments in his discipline or the confidence that a patient ought to have in the physician will obviously be eroded.

The mission of the new council is to expand education for better child care. To achieve this goal, we are planning to arrange educational workshops in all provinces. These will be arranged with the assistance of the provincial directors and consultant paediatricians. There will be a programme for nurses, teachers and parents as well. We have already conducted a successful workshop in Kandy on 'Children with Special Needs' in collaboration with UNICEF, Family Health Bureau and the Ministry of Health. These workshops will help us to reach not only paediatricians and paediatric trainees but also the medical officers, general practitioners and nursing officers who care for children in all parts of our country.

We hope to introduce a Nursing Congress to be held annually in parallel with the Annual Congress of the College. Update lectures of special topics of interest, symposia and courses to benefit postgraduate students are planned.

Overall, our aim will be to educate all those concerned in the health care of our children who will be the leaders of tomorrow.

\section{References}

1. Uhl H S M. A Brief History. In: Adrienne B. Rosof, William Campbell Felch, editors, Continuing Medical Education: A Primer, $2^{\text {nd }}$ ed. Greenwood: Prueger; 1986. pp.9-11.

2. Curtis N J. Management of urinary tract infections: historical perspective and current strategies: part 1-before antibiotics. The Journal of Urology, 173 (1): 21-6.
3. Curtis N J. Management of urinary tract infections: historical perspective and current strategies: part 2-modern management. The Journal of Urology, 173 (1): 27-32.

4. Robert Hutchison. Lectures on Diseases of Children. 6th Edition. London Edward Arnold \& Co. 1951

5. Royal College of Physicians. Guidelines for the management of acute urinary tract infection in childhood. Report of a Working Group of the research unit, Royal College of Physicians. $J R$ Coll Physicians London 1991; 25:36-42.

6. Consensus statement on management of urinary tract infections. Indian Paediatric Nephrology Group Indian Academy of Paediatrics. Indian Paediatrics 2001; 38:1106-15.

7. Practice Parameter: The Diagnosis, Treatment, and Evaluation of the Initial Urinary Tract Infection in Febrile Infants and Young Children American Academy of Pediatrics: Committee on Quality Improvement, Subcommittee on Urinary Tract Infection. Pediatrics 1999; 103(4): 843-52.

8. Abeysekera C. The child with urinary tract infection: a dilemma for the paediatrician Professor C. C. de Silva Oration 2004. Sri Lanka Journal of Child Health 2005; 34: 30-43

9. Woolf A S. A molecular and genetic view of human renal and urinary tract malformations Kidney International 2000; 58: 500-12.

10. Smellie J M, Barratt $\mathrm{T}$ M, Chantler $C$, et al. Medical versus surgical treatment in children with severe bilateral vesicoureteric reflex and reflux and bilateral nephropathy: a random trial. Lancet 2001;357:1329-33.

11. Abeysekera C K., Gunasekara W D V N, Abegunawardena A, Buthpitiya A G, Lamawansa M D, Fernando O, Goonasekera C D A. First experiences of paediatric kidney transplantation in Sri Lanka. Paediatric Transplantation 2007; 11(4):408-13. 